\title{
A Novel Neutral Point Clamped Full-Bridge Topology for Transformerless Photovoltaic Grid-Connected Inverters
}

\author{
Majid Pakdel \\ Department of Electrical Engineering \\ University of Zanjan \\ Zanjan, Iran \\ pakdel@znu.ac.ir
}

\author{
Saeid Jalilzadeh \\ Department of Electrical Engineering \\ University of Zanjan \\ Zanjan, Iran \\ jalilzadeh@znu.ac.ir
}

\begin{abstract}
This paper presents a novel neutral point clamped fullbridge topology for transformerless photovoltaic grid-tied inverters. Transformerless grid-connected inverters have been used widely in recent years since they offer higher efficiency and lower costs. Ground leakage current suppression is the main issue which should be considered carefully in transformerless photovoltaic grid-connected inverters. Among different methods used to decline ground leakage current, neutral point clamped (NPC) topologies are considered more useful and effective. In NPC topologies, the short-circuited output voltage at the freewheeling period is clamped to the middle of the DC bus voltage. Therefore, the common-mode voltage (CM) will be constant at the whole switching period. Various NPC topologies such as H6 [1], HB-ZVR [2], oH5 [3], and PN-NPC [4] have been proposed. In this paper, a novel NPC topology is proposed which has lower power losses and higher efficiency over previous topologies. Furthermore, the proposed NPC topology exhibits a similar ground leakage current with the PN-NPC topology. The proposed NPC topology is analyzed theoretically using simulation studies and an experimental prototype is provided to verify theoretical analysis and simulation studies.
\end{abstract}

Keywords-common-mode voltage (CMV); grid-connected inverter; ground leakage current; neutral point clamped (NPC) topology; photovoltaic (PV) generation system

\section{INTRODUCTION}

Due to the limit reservation of fossil fuels such as oil, coal, gas, etc. tendency to exploiting of renewable energy resources such as solar and wind energies have been growing rapidly worldwide. With recent reduction in prices of photovoltaic (PV) array modules and due to the excessive advancement of power electronics devices and technologies, grid-connected PV inverters have been playing an important role in distributed generation systems. Most of PV grid-connected inverters are designed with galvanic isolation using a bulky low frequency transformer connected to the grid voltage. Nevertheless of not flowing ground leakage current in a grid-tied inverter with the galvanic isolation, however, the total price and space required to the grid-connected inverter will be very high as well as its efficiency will be very low. To overcome these drawbacks, transformerless grid-tied inverters have been introduced.
Among the different methods used to decline ground leakage current, neutral point clamped (NPC) topologies are considered more useful and effective. In NPC topologies, the short circuited output voltage at the freewheeling period is clamped to the middle of the DC bus voltage. Therefore, the commonmode voltage (CM) will be constant at the whole switching period. Various NPC topologies such as H6 [1], HB-ZVR [2], oH5 [3], and PN-NPC [4] have been proposed. Various topologies have been proposed for the reduction of ground leakage current in transformerless grid-tied inverters [5-19]. In this paper, a novel NPC topology is proposed which has lower power losses and higher efficiency over previous topologies. Furthermore, the proposed NPC topology exhibits similar ground leakage current with the PN-NPC topology. The proposed NPC topology is analyzed theoretically using simulation studies and an experimental prototype is provided to verify theoretical and simulation studies.

The main disadvantage of a transformerless grid-tied inverter is that ground leakage current is produced because of common- mode voltage variations in switching periods. The common-mode and differential-mode in a transformerless gridtied inverter are defined as follows [6]:

$$
\begin{aligned}
& V_{C M}=\frac{1}{2}\left(V_{A N}+V_{B N}\right) \\
& V_{D M}=V_{A N}-V_{B N}
\end{aligned}
$$

Therefore, we have the following equations [6]:

$$
\begin{aligned}
& \boldsymbol{V}_{A N}=\frac{1}{2} \boldsymbol{V}_{C M}+V_{D M} \\
& V_{B N}=\frac{1}{2} V_{C M}-V_{D M}
\end{aligned}
$$

Furthermore, using the Thevenin's theorem, the commonmode (CM) voltage equivalent circuit which produces the ground leakage current can be constructed, from which the total CM voltage is calculated as follows [6]:

$$
V_{t C M}=V_{C M}+\frac{V_{D M}}{2}\left(\frac{L_{B}-L_{A}}{L_{B}+L_{A}}\right)
$$


Usually, $L_{A}=L_{B}$, therefore, the following relation is satisfied:

$$
V_{t C M}=V_{C M}=\frac{1}{2}\left(V_{A N}+V_{B N}\right)=\text { Const. }
$$

Leakage current standard according to VDE 0126-1-1 is depicted in Table I.

TABLE I. LEAKAGE CURRENT STANDARD ACCORDING TO VDE 0126-1-1

\begin{tabular}{|c|c|}
\hline Leakage Current Value (mA) & Disconnection Time (s) \\
\hline 30 & 0.3 \\
\hline 60 & 0.15 \\
\hline 100 & 0.04 \\
\hline
\end{tabular}

\section{NEUTRAL POINT CLAMPED FULL-BRIDGE TOPOLOGIES}

In neutral point clamped (NPC) full-bridge topologies, the short circuited output voltage at freewheeling period is clamped to the middle of the DC bus voltage. Therefore, the commonmode (CM) voltage will be constant in the whole switching period. The H6 [1] topology consists of two switches and a bidirectional branch with a capacitive divider and two diodes which clamp the CM voltage to the half of input DC voltage. In this topology, the leakage current suppression is only dependent to the turn on speed of clamping diodes. A main drawback of this topology is its higher conducting losses. Since, the inductor current flows through four switches in active mode. Another NPC full-bridge topology with AC bypass is the HB-ZVR topology [2]. In this topology, the short circuited output voltage at the freewheeling period is clamped to the middle of the DC bus voltage using a diode rectifier and a bidirectional switch. To prevent short circuiting of the lower capacitor in the capacitive divider, a diode is added. Neutral point clamping condition is provided by short circuiting of inverter output in freewheeling period. The main drawback of this topology is that clamping using a diode is done when the freewheeling voltage is greater than the middle point of input DC bus. Therefore, the variations of CM voltage in reverse condition will happen. In case of the oH5 topology [3], the main disadvantage of this topology is that the inductor current flows through three switches in active mode; therefore, there will be more conducting losses. The last NPC topology is the PN-NPC topology [4]. In this topology, two switching cells i.e. positive neutral point clamped (P-NPC) cell and negative neutral point clamped (N-NPC) are combined to make the PNNPC topology. The operation principle of PN-NPC topology is similar to H6 topology. The CM voltage is kept constant at half of the input DC voltage. The main drawback of this topology is the existence of high number of switches and higher conductive losses since, in the worst condition the inductor current flows through four switches in the active mode.

\section{PROPOSED NEUTRAL POINT CLAMPED FULL-BRIDGE TOPOLOGY}

A variant NPC full-bridge topology with its modulation strategy is proposed in this paper. The proposed topology and the control circuit for generating the drive signals are illustrated in Figures 1 and 2. The main idea is clamping the short circuit output voltage at the freewheeling period to the middle of the
DC input voltage. The control and modulation strategy for triggering the power switches is as follows: during the positive half cycle, the power switches Q1 and Q4 are turned on and turned off with switching frequency (Q2, Q3 and Q5 are off). When both Q1 and Q4 are turned off, the power switch Q6 is turned on and vice versa i.e. while Q1 and Q4 are turned on, Q6 is turned off (with the switching frequency).

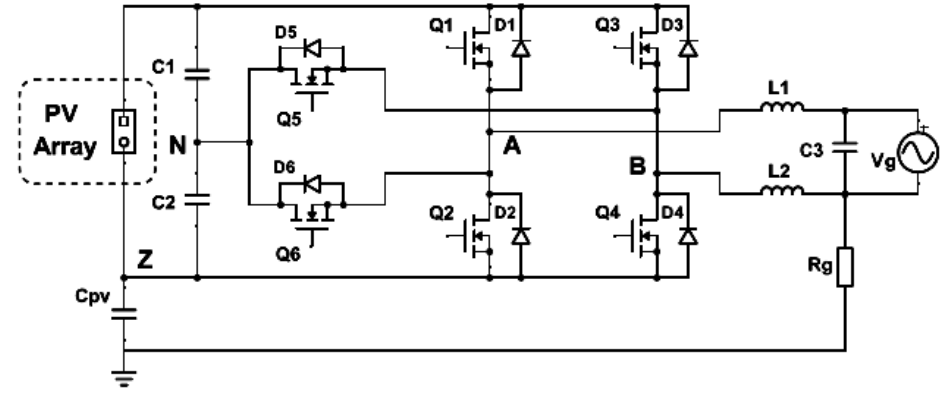

Fig. 1. Proposed single phase transformerless NPC topology

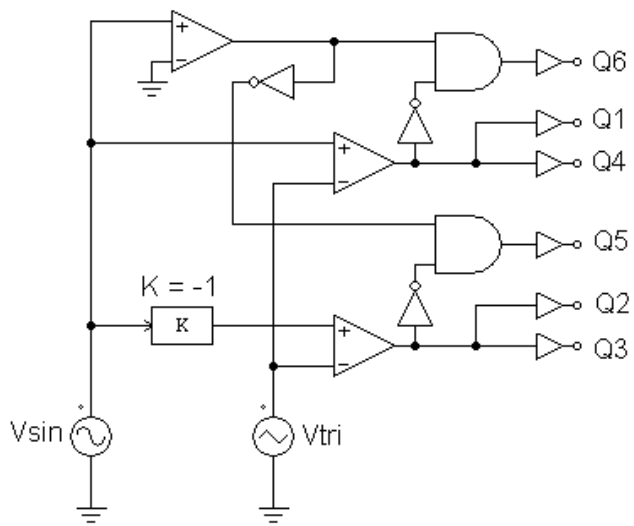

Fig. 2. Control and modulation circuit of proposed NPC topology

Therefore, in active mode (during positive half cycle) the current flows in the route Q1-L1-Vg-L2-Q4. During the freewheeling period, the current flows in the route Q6-L1-VgL2-D5. As a result, the CM voltage is clamped to the half of the DC input voltage. Therefore the ground leakage current is decreased significantly. During the negative half cycle, the power switches Q2 and Q3 are turned on and turned off with switching frequency (Q1, Q4 and Q6 are off). When both Q2 and Q3 are turned off, the power switch Q5 is turned on and vice versa i.e. while Q2 and Q3 are turned on, Q5 is turned off (with switching frequency). Therefore, in active mode (during negative half cycle) the current flows in the route Q3-L2-VgL1-Q2. During the freewheeling period, the current flows in the route Q5-L2-Vg-L1-D6. As a result, the CM voltage is clamped to the half of input DC voltage. Therefore, the ground leakage current is declined significantly. The analysis of the $\mathrm{CM}$ equivalent circuit for the proposed topology to obtain the CM voltage which is defined in (6) as the sum of output terminal voltages to the NPC, the following relation is satisfied: 


$$
\mathrm{V}_{\mathrm{CM}}=\frac{\mathrm{V}_{\mathrm{AZ}}+\mathrm{V}_{\mathrm{BZ}}}{2}
$$

The CM voltage related to the positive, negative and neutral vectors can be portrayed as follows:

$$
\text { Positive: } \mathrm{V}_{\mathrm{CM}}=\frac{\mathrm{V}_{\mathrm{AZ}}+\mathrm{V}_{\mathrm{BZ}}}{2}=\frac{\mathrm{V}_{\mathrm{DC}}+0}{2}=\frac{\mathrm{V}_{\mathrm{DC}}}{2}
$$

Neutral: $\mathrm{V}_{\mathrm{CM}}=\frac{\mathrm{V}_{\mathrm{AZ}}+\mathrm{V}_{\mathrm{BZ}}}{2}=\frac{\mathrm{V}_{\mathrm{DC}} / 2+\mathrm{V}_{\mathrm{DC}} / 2}{2}=\frac{\mathrm{V}_{\mathrm{DC}}}{2}$

Negative: $\mathrm{V}_{\mathrm{CM}}=\frac{\mathrm{V}_{\mathrm{AZ}}+\mathrm{V}_{\mathrm{BZ}}}{2}=\frac{0+\mathrm{V}_{\mathrm{DC}}}{2}=\frac{\mathrm{V}_{\mathrm{DC}}}{2}$

As illustrated in equations (8) to (10), the CM voltage remains constant in different switching conditions. Therefore, a very small ground leakage current should be expected to flow through PV stray capacitors.

\section{SimUlation RESUlts}

The proposed topology and control strategy were tested by simulation analysis with the parameters illustrated in Table II. Load current, the voltage measured between the grid terminal and ground (Leakage Voltage) and the leakage current are shown in Figures 3-5 respectively. As shown, the load current is very close to a sinusoidal waveform which leads to a low $\mathrm{dv} / \mathrm{dt}$. It means that the leakage current will be low as depicted in the Figure 5. Therefore, the maximum leakage current is below $100 \mathrm{~mA}$ that comply with the standard DIN VDE 01261-1 as pointed in Table I.

\section{EXPERIMENTAL RESULTS}

An experimental prototype of the proposed grid tied inverter was made and its operation was tested as depicted in Figure 6 . The inverter output voltage and its ground leakage current are shown in Figure 7. As illustrated in Figure 7, the ground leakage peak current same as the simulation result is below $100 \mathrm{~mA}$ that comply with the standard DIN VDE 01261-1 mentioned in Table I.

\section{CONCLUSION}

A novel neutral point clamped full-bridge topology was proposed for transformerless photovoltaic grid-tied inverters. Transformerless grid-connected inverters have been using widely nowadays since, they offer higher efficiency and lower economic cost. Ground leakage current suppression is the main issue that should be considered in transformerless photovoltaic grid-connected inverters. Different methods have been employed to reduce ground leakage current in grid tied inverters. Neutral point clamped (NPC) topologies are considered more useful and effective. In NPC topologies, the short-circuited output voltage at the freewheeling period is clamped to the middle of the DC bus voltage. Therefore, the common-mode voltage (CM) will be constant at the whole switching period resulting to a very small ground leakage current. The proposed NPC topology exhibits a similar ground leakage current with the PN-NPC topology. The proposed NPC topology was tested using simulation studies and an experimental prototype was also implemented to verify the results.

TABLE II. SIMULATION CIRCUIT PARAMETERS

\begin{tabular}{|c|c|}
\hline Circuit Parameters & Values \\
\hline $\mathrm{C}_{1}$ & $10 \mu \mathrm{F}$ \\
\hline $\mathrm{C}_{2}$ & $10 \mu \mathrm{F}$ \\
\hline $\mathrm{L}_{1}$ & $2.2 \mu \mathrm{H}$ \\
\hline $\mathrm{L}_{2}$ & $2.2 \mu \mathrm{H}$ \\
\hline $\mathrm{C}_{3}$ & $4.7 \mu \mathrm{F}$ \\
\hline $\mathrm{R}_{\mathrm{g}}$ & $1 \mathrm{ohm}$ \\
\hline $\mathrm{C}_{\mathrm{PV}}$ & $1 \mathrm{nF}$ \\
\hline $\mathrm{f}_{\mathrm{SW}}$ & $50 \mathrm{kHz}$ \\
\hline
\end{tabular}

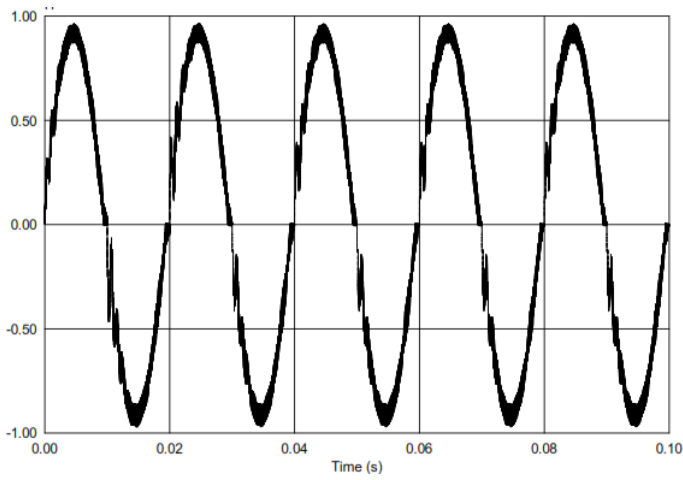

Fig. 3. Load current

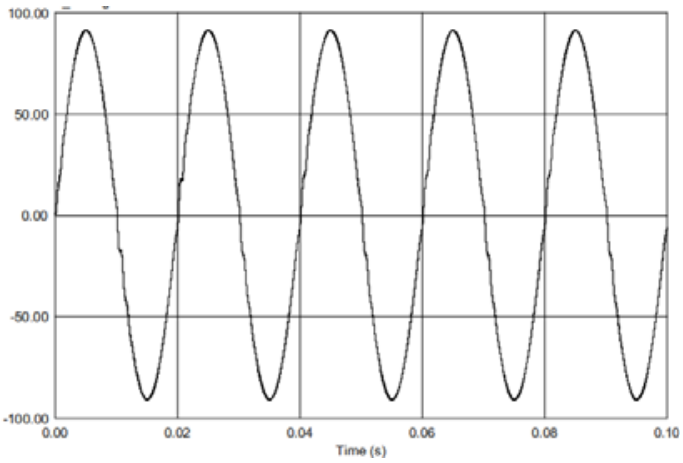

Fig. 4. Leakage voltage

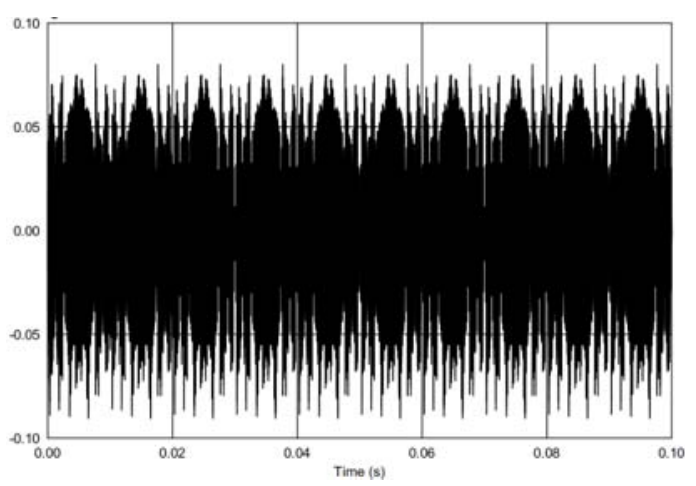

Fig. 5. Leakage current 


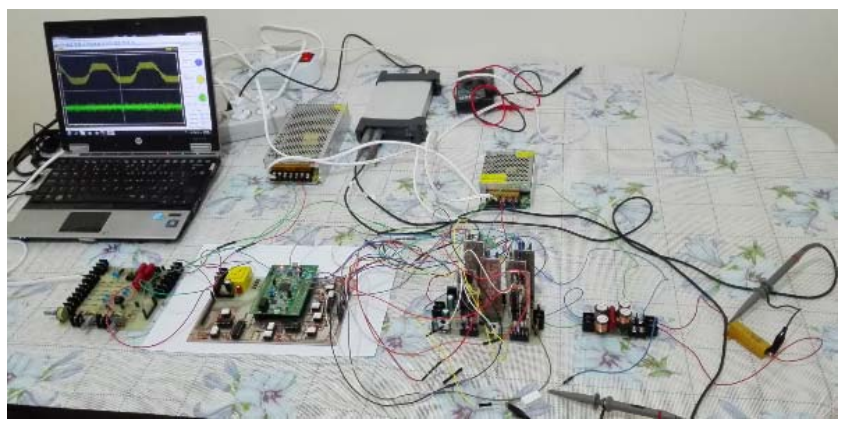

Fig. 6. Experimental setup for the proposed grid tied inverter

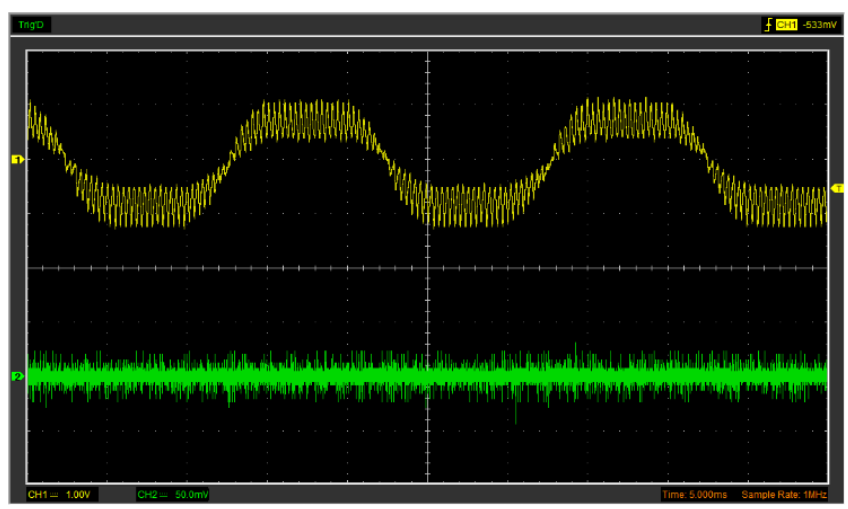

Fig. 7. Inverter output voltage and its ground leakage current

\section{REFERENCES}

[1] R. Gonzalez, J. Lopez, P. Sanchis, L. Marroyo, "Transformerless inverter for single-phase photovoltaic systems", IEEE Transactions on Power Electronics, Vol. 22, No. 10, pp. 693-697, 2007

[2] T. Kerekes, R. Teodorescu, P. Rodríguez, G. Vázquez, E. Aldabas, “A new high-efficiency single-phase transformerless PV inverter topology", IEEE Transactions on Industrial Electronics, Vol. 58, No. 1, pp. 184191, 2011

[3] H. Xiao, S. Xie, Y. Chen, R. Huang, “An optimized transformerless photovoltaic grid-connected inverter”, IEEE Transactions on Industrial Electronics, Vol. 58, No. 5, pp. 1887-1895, 2011

[4] L. Zhang, K. Sun, L. Feng, H. Wu, Y. Xing, “A family of neutral point clamped full-bridge topologies for transformerless photovoltaic grid-tied inverters", IEEE Transactions on Power Electronics, Vol. 28, No. 2, pp. 730-739, 2013

[5] D. Barater, E. Lorenzani, C. Concari, G. Franceschini, G. Buticchi, "Recent advances in single-phase transformerless photovoltaic inverters”, IET Renewable Power Generation, Vol. 10, No. 2, pp. 260273, 2016

[6] M. Islam, S. Mekhilef, M. Hasan, "Single phase transformerless inverter topologies for grid-tied photovoltaic system: a review”, Renewable and Sustainable Energy Reviews, Vol. 45, pp. 69-86, 2015

[7] M. Victor, F. Greizer, S. Bremicker, U. Hübler, "Method of converting a direct current voltage from a source of direct current voltage, more specifically from a photovoltaic source of direct current voltage, into a alternating current voltage”, U.S. Patent 7,411,802, 2008

[8] S. Christoph, K. Jurgen, "Inverter for transforming a DC voltage into an AC current or an AC voltage”, Europe Patent 1, No. 369, p. 985, 2003

[9] W. Yu, J. S. J. Lai, H. Qian, C. Hutchens, "High-efficiency MOSFET inverter with H6-type configuration for photovoltaic nonisolated ACmodule applications", IEEE Transactions on Power Electronics, Vol. 26, No. 4, pp. 1253-1260, 2011

[10] B. Yang, W. Li, Y. Gu, W. Cui, X. He, "Improved transformerless inverter with common-mode leakage current elimination for a photovoltaic grid-connected power system", IEEE Transactions on Power Electronics, Vol. 27, No. 2, pp. 752-762, 2012

[11] B. Gu, J. Dominic, J. S. Lai, C. L. Chen, T. LaBella, B. Chen, "High reliability and efficiency single-phase transformerless inverter for gridconnected photovoltaic systems", IEEE Transactions on Power Electronics, Vol. 28, No. 5, pp. 2235-2245, 2013

[12] S. Bremicker, F. Greizer, M. Victor, "Inverter, more specifically for photovoltaic plants”, U.S. Patent 7.843,714, 2010

[13] M. Xu, L. Zhang, Y. Xing, L. Feng, “A novel H6-type transformerless inverter for grid-connected photovoltaic application”, 7th IEEE Conference on Industrial Electronics and Applications (ICIEA), pp. 5863, 2012

[14] J. Wang, B. Ji, J. Zhao, J. Yu, “From H4, H5 to H6-Standardization of full-bridge single phase photovoltaic inverter topologies without ground leakage current issue”, IEEE Energy Conversion Congress and Exposition (ECCE), pp. 2419-2425, 2012

[15] J. M. Shen, H. L. Jou, J. C. Wu, "Novel transformerless grid-connected power converter with negative grounding for photovoltaic generation system», IEEE Transactions on Power Electronics, Vol. 27, No. 4, pp. 1818-1829, 2012

[16] D. Dong, F. Luo, D. Boroyevich, P. Mattavelli, "Leakage current reduction in a single-phase bidirectional AC-DC full-bridge inverter", IEEE Transactions on Power Electronics, Vol. 27, No. 10, pp. 4281-4291, 2012

[17] L. Zhang, K. Sun, Y. Xing, M. Xing, "H6 transformerless full-bridge PV grid-tied inverters”, IEEE Transactions on Power Electronics, Vol. 29, No. 3, pp. 1229-1238, 2014

[18] W. Cui, B. Yang, Y. Zhao, W. Li, X. He, "A novel single-phase transformerless grid-connected inverter”, 37th Annual Conference on IEEE Industrial Electronics Society, pp. 1126-1130, 2011

[19] S. V. Araujo, P. Zacharias, B. Sahan, "Novel grid-connected nonisolated converters for photovoltaic systems with grounded generator», IEEE Power Electronics Specialists Conference, pp. 58-65, June, 2008 